ISSN 1984-3372

http://portaldeperiodicos.unisul.br/index.php/EeN/index

\title{
INFLUÊNCIA NO PROCESSO DE COMPRAS EM SUPERMERCADOS: UM ESTUDO EXPLORATÓRIO COM CLIENTES APOSENTADOS
}

\section{INFLUENCE IN THE SHOPPINGPROCESS INSIDE THE SUPERMARKET: AN EXPLORATORY STUDY WITH RETIREDCUSTOMERS}

\section{Márcio Moutinho Abdalla}

Doutorando em administração pela FGV-EBAPE

Professor da Universidade Federal Fluminense e professor na Universidade Aberta do Brasil (UAB)

Endereço: Rua Des. Ellis Hermydio Figueira, 783 - Bloco A, Aterrado. CEP: 27213-415. Volta Redonda, RJ, Brasil Telefone: (24) 3076-8777

E-mail: marciomabdalla@yahoo.com.br

\section{Henrique Lourenço Pena}

Graduado em Administração pela Universidade Federal Fluminense Professor de Administração do PRONATEC Muriaé Escola Estadual Orlando Flores

Endereço: Rua Des. Ellis Hermydio Figueira, 783 - Bloco A, Aterrado. CEP: 27213-415. Volta Redonda, RJ, Brasil Telefone: (24) 3076-8867

E-mail: henrique@irmaos.com

Artigo recebido em 27/02/2013. Revisado por pares em 07/06/2013. Reformulado em 07/11/2013. Recomendado para publicação em 29/11/2013 por Ademar Dutra (Editor Científico). Publicado em 20/12/2013. Avaliado pelo Sistema double blind review.

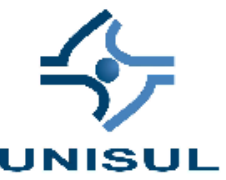




\section{RESUMO}

Com as mudanças no mercado globalizado brasileiro nos últimos anos, principalmente de supermercados, o comportamento do consumidor veio sofrendo algumas alterações. Mediante o incremento no poder de compra da terceira idade, supermercados identificaram a necessidade de atender, em especial, aos desejos específicos deste grupo de consumidores. Assim, este estudo tem, como objetivo, explorar as categorias de influência no processo de compra em supermercado sob o olhar de clientes aposentados. Para a consecução do objetivo, optou-se pela coleta de informações por meio de grupos focais. As opiniões apresentadas pelos aposentados foram analisadas através de análise de conteúdo, levando-se em consideração categorias previamente observadas na literatura, além de categorias emergentes. Como resultado, observou-se que, embora preço e localização sejam elementos relevantes, não se caracterizam mais como fatores determinantes de escolha. Aparentemente, a satisfação está direcionada ao atendimento e à qualidade dos serviços de cada setor. Este grupo de consumidores destaca-se pela disposição em vivenciar novas experiências de compra.

Palavras-chave: Comportamento consumidor; Terceira idade; Varejo; Grupo focal.

\section{ABSTRACT}

With changes in the global market Brazil in recent years, mainly supermarkets, consumer behavior have undergone some changes. By increasing the purchasing power of the elderly, supermarkets identified the need to meet the specific desires, especially from this consumer group. Hence, this study aims to explore the categories of influence on the shopping process in supermarket, under the gaze of retirees' consumers. To achieve the goal, we chose to collect information through focus groups. The opinions expressed by retirees were analyzed through content analysis, taking into account categories previously observed in the literature, besides emerging categories. As a result, it was observed that although price and location are relevant factors, they are not characterize as determinants of choice any more. Apparently, satisfaction is directed for care and quality services from each sector. This consumer group is distinguished by willingness to live new shopping experiences.

Keywords: Consumer behavior; Seniors; Retail; Focus group.

\section{INTRODUÇÃO}

Com a facilidade de crédito e o equilíbrio da economia brasileira, o consumidor passou a frequentar mais supermercados, evitando grandes armazenamentos e comprando mais vezes durante o mês. Durante esse tempo, o consumidor acumula informações das experiências vividas cada vez que vai ao supermercado, além de tornar-se mais crítico na escolha da sua preferência de compra. O consumidor está disposto a avaliar diversos tópicos com o objetivo de satisfazer suas necessidades. A globalização da economia e a estabilização 
econômica permitiram que hipermercados e supermercados passassem por diversas mudanças que atendessem à diversidade de comportamentos de consumidores. Essa mudança passou a ser mais nítida devido à internacionalização de supermercados que também se instalaram no Brasil.

De acordo com Furuta (2002), o varejo é um importante objeto de estudo no meio acadêmico, que vem crescendo em números e estudos. O comércio varejista tem ganhado espaço em todo o Brasil e os olhos do mundo voltaram para o país, como uma aposta de grandes investimentos.

O consumidor está atualmente diante de diferentes formatos de varejo que atendam às suas necessidades. Dados da Associação Brasileira de Supermercados (ABRAS) apontam que em 2011 o setor contava com aproximadamente 82 mil supermercado no Brasil. O ranking também apontou que o setor em 2011 alcançou faturamento de 224,3 bilhões de reais (CASTRO; FERREIRA, 2012). Para Camarotto (2009), faz-se necessário que o varejista estude e compreenda o comportamento do consumidor, uma vez que as decisões de compra dos clientes ocorrem com mais frequência no ambiente da loja. Para que um estudo desses seja feito, devem-se levar em conta as atividades físicas, mentais e emocionais relacionadas a compra e uso dos produtos. Nesse sentido, a principal motivação para condução do estudo reside na vivência de um dos autores no setor, visto que sua família é proprietária de um supermercado. A escolha do público, dentre outras questões, é justificada pelo próprio envelhecimento da população brasileira, percebido pelo perfil de cliente frequentador do supermercado.

Diante do exposto e das categorias identificadas através da literatura, o objetivo central desta pesquisa é explorar, por meio de um estudo qualitativo, quais dessas categorias são de influência no processo de compra em supermercados por clientes aposentados. Buscou-se atender ao objetivo por meio do desenvolvimento de grupos focais como técnica de coleta de dados e emprego de análise de conteúdo, para tratamento das informações.

Este estudo é dividido em mais quatro partes. No tópico seguinte é feito um levantamento bibliográfico que visa a cobrir o foco do estudo. O terceiro tópico encarrega-se de expor as características metodológicas empregadas no trabalho. O quarto item compõe- 
se da análise dos resultados da pesquisa. As considerações finais são apresentadas no quinto tópico.

\section{REFERENCIAL TEÓRICO}

Esse referencial teórico desenvolve uma breve contextualização da chegada dos grandes varejistas ao Brasil, um estudo do comportamento do consumidor quanto à decisão de compra e um levantamento bibliográfico das categorias tratadas na literatura, como tópicos de decisão de compra em supermercados.

\subsection{O VAREJO NO BRASIL}

Um exemplo de hipermercado internacional que viu a oportunidade de crescimento no Brasil é o Carrefour. Fundado na França, a organização escolheu o Brasil para ser o primeiro país na América a recebê-la. Em 1975 os franceses tiveram uma estratégia arriscada: adquiriram redes já existentes e reconhecidas pelos brasileiros, como a Eldorado, algumas unidades das Lojas Americanas e muitas outras redes regionais. O comportamento do consumidor dessas redes adquiridas e a cultura do país eram bem diferentes do mercado francês, assim como a diferença do poder de compra (HONORATO, 2004). Em 1999, o Carrefour adquiriu mais 85 lojas nacionais, entre elas os supermercados da Rede Champion, Planaltão e Mineirão, criando assim uma nova bandeira da organização: o Carrefour Bairro. Na busca por reconquistar a liderança do varejo que foi perdida para o Grupo Pão de Açúcar, o Carrefour viu como solução a compra da Rede Atacadão em 2000 (DABDAB WAQUIL; MIELE; SCHULTZ, 2010), pelo montante de 2,2 bilhões de reais.

Adotando a estratégia corporativa internacional, a empresa americana WalMart, desde 1995 no Brasil, viu o país como a oportunidade que a empresa tanto sonhava, uma vez que o país conta coma quinta maior população do mundo e com a tendência de seguir a cultura americana. O Wal-Mart também optou pela estratégia de crescimento não orgânico, adquirindo supermercados já existentes no país. O grupo buscou ofertar experiências marcantes ao consumidor, já que neste tipo de varejo, o que se oferece é a oportunidade de se comprar tudo em um só lugar. A internacionalização é uma vantagem, Revista Eletrônica de Estratégia \& Negócios, Florianópolis, v.6, n.3, set./dez.2013. 
mas pode trazer grandes riscos. Para Simchi-levi, Kaminsky e Simchi-Levi (2003), quando a rede Wal-Mart veio para o Brasil, trouxe equipamento de estoque que não funcionava com os paletes (armazenagem para depósitos) disponíveis aqui no Brasil, além de instalar um sistema de contabilidade computadorizado que falhou, em virtude de o sistema de tributos no Brasil ser distinto do norte-americano.

Rubinfeld e Hemingway (2005) destacam o caso das estratégias das lojas que chegaram ao Brasil: o varejo não tinha que se adaptar ao comportamento dos consumidores e nem propor um conceito que mudasse o comportamento do brasileiro, mas sim construir um novo conceito a partir do que é existente na localização onde será instalado o supermercado, um processo que leva tempo, no decorrer da instalação do supermercado. Como mostram os autores Kotabe e Leal (2001), os hipermercados tinham um formato basicamente desconhecido no Brasil. Na busca de satisfação, o consumidor almejava uma agradável experiência de compra, em uma atmosfera que atendesse às suas necessidades, mas ele se mostrou disposto a vivenciar novas experiências neste ambiente. Isso pode ser explicado pelo conhecimento e as experiências que os consumidores vêm adquirindo ao longo do tempo. Seja um produto ou serviço, os clientes atribuem características cada vez mais rígidas. Por exemplo: para o estacionamento do supermercado observam-se a segurança, as filas de carro, a limpeza e a iluminação. Para o serviço de açougue, julgam-se atributos de qualidade dos frios, higiene do local, procedência dos frios e aspecto dos açougueiros. Isso é cada vez mais evidente nas pesquisas de comportamento do consumidor. Um produto ou serviço pode ter muitos atributos, além de fatores empíricos e extrínsecos. Além disso, é possível medir a relevância que os consumidores dão ao escolher quais atributos utilizam quando vão às compras.

São as lojas de vizinhança que veem a oportunidade de crescimento. Os supermercados de poucos check-outs hoje estão trabalhando e oferecendo serviços cada vez mais semelhantes. Como as grandes redes, esses pequenos mercados buscam criar atrativos e fidelizar cada vez mais os seus clientes. O lugar que antes havia sido perdido com a chegada das lojas internacionais de alto nível de competitividade voltou a ser das pequenas lojas que conseguiram sobreviver (ALMEIDA, 2007). As lojas de vizinhança têm essa característica, buscam a preferência do consumidor e, cada vez mais, conhecem os reais interesses dos clientes.

Revista Eletrônica de Estratégia \& Negócios, Florianópolis, v.6, n.3, set./dez.2013. 


\subsection{A DECISÃO DE COMPRA}

O comportamento do consumidor é definido como as atividades físicas e mentais vividas pelo cliente. Isso resulta nas decisões diretamente envolvidas em obter, dispor e consumir produtos. As atividades mentais ocorrem quando o consumidor julga a qualidade de uma marca, faz inferência sobre a qualidade de um produto baseado nas informações veiculadas em propaganda e avalia as experiências com aquele produto. Por sua vez, as atividades físicas configuram-se em ir até o supermercado, conversar com os vendedores, ou ainda, emitir um pedido de compra (SHETH; MITTAL; NEWMAN, 2001).

Identificar o motivo que leva o consumidor ao estabelecimento é o ponto inicial para criar qualquer estratégia de venda. Por exemplo, para um consumidor que realiza compras para o seu trabalho, é preciso que seja atendido com rapidez, sem falhas e com facilidade de localização dos produtos. Blackwell, Miniard e Engel (2005) mostram que as pessoas podem comprar por motivos pessoais e sociais. Levam em conta os motivos pessoais como atividade física, estimulação sensorial, auto gratificação e diversão, além dos motivos sociais, que se configuram em ter experiências fora de casa, atração por um grupo de amigos, barganha, status e autoridade.

A figura 1 demonstra o processo de decisão de compra e, por conseguinte, o processo de escolha de uma loja, simulando como o consumidor normalmente decide onde realizar as suas compras. 
Figura 1 - Decisão de Compra

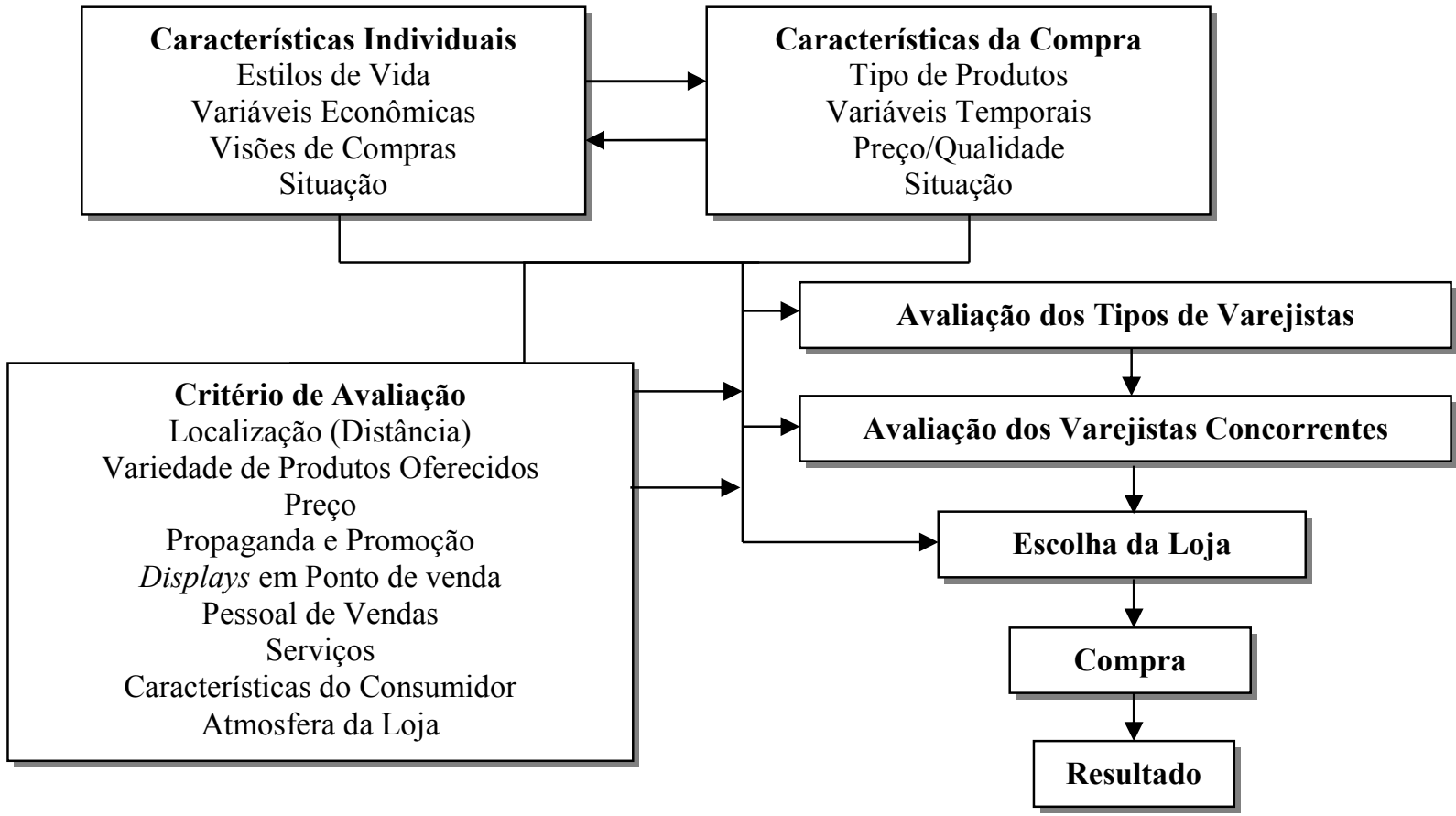

Fonte: Blackwell, Miniard e Engel. (2005, p. 137).

Para identificar as categorias do referencial teórico, este estudo realizou uma revisão da literatura na busca de material que apresentasse razões de escolha de supermercado e o comportamento desse consumidor, em especial no Google Acadêmico, em periódicos qualificados, livros de referência, além de anais de eventos como EnANPAD. As categorias coincidentes entre esses estudos contribuíram para a estruturação do quadro teórico (quadro 1), que apresenta categorias, autores e questões qualitativas em comum.

Quadro 1 - Revisão de Literatura

\begin{tabular}{|l|l|l|}
\hline Categoria & Questões Qualitativas & Referências \\
\hline Preço & $\begin{array}{l}\text { Satisfação do consumidor quando o preço fica abaixo do seu } \\
\text { orçamento. O consumidor comprando em supermercados de } \\
\text { rede tem a possibilidade de obter produtos de menor preço } \\
\text { em virtude do maior volume. Preço do produto é o principal } \\
\text { fator em consideração apontado em estudos. }\end{array}$ & $\begin{array}{l}\text { Davies, Goode, Moutinho e } \\
\text { Ogbonna (2001); Ferreira } \\
\text { Júnior e Teixeira (2007); } \\
\text { Campolina et al. (2007); } \\
\text { Kotler (2001). }\end{array}$ \\
\hline $\begin{array}{l}\text { Serviços } \\
\text { prestados }\end{array}$ & $\begin{array}{l}\text { Os serviços do supermercado estão de acordo com a cultura } \\
\text { do consumidor e a localização do estabelecimento. } \\
\text { Estacionamento, restaurante, caixas eletrônicos, entrega em } \\
\text { domicílio entre outros. }\end{array}$ & $\begin{array}{l}\text { Davies, Goode, Moutinho e } \\
\text { Ogbonna (2001). }\end{array}$ \\
\hline Atendimento & $\begin{array}{l}\text { O consumidor está disposto a pagar mais caro para ter } \\
\text { atendimento diferenciado, variedade, status e conveniência. }\end{array}$ & Parente (2000) \\
\hline
\end{tabular}

Revista Eletrônica de Estratégia \& Negócios, Florianópolis, v.6, n.3, set./dez.2013. 


\begin{tabular}{|l|l|l|}
\hline \multicolumn{1}{|l|}{} & $\begin{array}{l}\text { O atendimento personalizado é um processo de longo prazo } \\
\text { na organização. Os consumidores sentem falta do } \\
\text { atendimento diferenciado nas pequenas lojas, querem } \\
\text { comodidade e satisfação. }\end{array}$ & \\
\hline Localização & $\begin{array}{l}\text { A proximidade da residência do consumidor faz com que ele } \\
\text { frequente mais vezes o supermercado. Em razão desta } \\
\text { tendência os lojistas dispõem de ofertas diárias. Fator } \\
\text { determinante para volume de vendas diário, e com } \\
\text { movimentação de pessoas durante todo o mês. }\end{array}$ & $\begin{array}{l}\text { Campolina et al. (2007); } \\
\text { Parente (2000). }\end{array}$ \\
\hline
\end{tabular}

Fonte: Elaborado pelos autores, 2013.

\subsubsection{Preço}

Para Kotler e Keller (2006) dentre o mix de marketing, o preço é o único capaz de produzir receita diretamente. Os demais elementos trazem custos para a organização, já que a receita é obtida indiretamente. Inicialmente o preço era conhecido como "barganha" e essa relação entre compradores e vendedores ainda se faz presente no comércio cotidiano. Mas o preço não deixou de ser o determinante para escolha de compra do consumidor, ele permanece como um dos elementos fundamentais na participação do mercado e lucratividade das empresas. Os consumidores saem de casa dispostos a pagarem um determinado valor pelo seu produto e, portanto, agem com cautela.

O preço é o grande influenciador no caixa da empresa. A estratégia de um supermercado pode ser demonstrada pelo valor do produto. Conhecidos como "especialistas em preço", os estrategistas na busca por maiores resultados personalizam os preços e as ofertas com base no valor e nos custos do mercado. Foram realizados muitos estudos referentes a preço (e.g. STIVING; WINER, 1997; SCHINDLER; KIRBY, 1997), o que permitiu que essa estratégia fosse aproveitada pelos especialistas. As pesquisas desses autores mostravam diversos significados do preço para o cliente. Os consumidores tendem a memorizar os preços lidos da esquerda para a direita, como, por exemplo, um quilo de picanha que custe $\mathrm{R} \$ 19,99$ para o cliente está na casa dos $\mathrm{R} \$ 10,00$ e não na casa de $\mathrm{R} \$ 20,00$, ou seja, o cliente não arredonda o preço. Os números quebrados transmitem a ideia de pechinha aos consumidores. Um estudo feito na França, evidenciou que a venda de uma pizza, que antes custava EUR 8,00 , subiu $15 \%$ nas vendas ao mudar o preço para EUR 7,99 (POUNDSTONE, 2010). 
Para produtos com imagem de alto preço, é necessário que se evitem números quebrados, como, por exemplo, para uma garrafa de vinho, cujo preço é $R \$ 160,00$. Um estudo mostrou que preços que terminem com zero e cinco são mais fáceis de serem memorizados pelos consumidores, pois são comuns de serem encontrados em qualquer outro supermercado (ANDERSON; SIMESTER, 2003). O preço promocional deve ser usado com bom senso em itens que o consumidor não conhece muito bem (pouca frequência de compra, lançamento de produto no mercado, produtos sazonais e para quando a qualidade e o tamanho de um produto variam de uma loja para outra).

De acordo com Anderson e Simester (2004), o preço funciona como a quantidade de dinheiro que devemos sacrificar para adquirir algo que desejamos e, para o consumidor realizar esse sacrifício, precisa ter capacidade para o mesmo. Quanto o consumidor está disposto a gastar e o seu tipo de compra durante um período reflete sua "restrição orçamentária". De acordo com a pesquisa de Schindler (2012), 42,9\% dos preços nos encartes de propaganda do varejo americano terminavam em "99". O varejista, sabendo da necessidade do seu consumidor, oferece ao cliente variações e possibilidades diferenciadas de pagamento (DIAMANTIPOULOS, 2005).

\subsubsection{Atendimento}

Sheth, Mittal e Newman (2001) dividem a fase do atendimento em pré e póscompra. Os varejistas são os responsáveis por agregarem valor para a fase de pré-compra. São os funcionários da loja, no atendimento, que informam e ajudam o cliente a avaliar suas necessidades na aquisição do produto. Aquele supermercado que se apresenta de modo superior, diferencia-se dos seus concorrentes. Por exemplo, no açougue, que exige excelente tratamento com o cliente, ter informações sobre as carnes e cortes, o atendimento e a satisfação do consumidor vão além do balcão, como cuidados de limpeza do local de trabalho e do funcionário (ALLARCON, 2010).

A rede de supermercados Bretas, localizada nas Minas Gerais, em 1996 resolveu investir alto no desenvolvimento profissional de seus colaboradores e criou um Centro de Treinamento, onde a formação de profissionais cria um vínculo mais forte junto aos funcionários e possibilita um maior entendimento a respeito das políticas e diretrizes de Revista Eletrônica de Estratégia \& Negócios, Florianópolis, v.6, n.3, set./dez.2013. 
operação de trabalho da rede. Isso proporcionou à equipe de trabalho uma atmosfera confortável no ambiente de trabalho. A ideia é repassada na forma de atendimento ao consumidor. A rede não para de crescer e no ponto de venda o atendimento é diferenciado (CURTY, 2009).

Ter um profissional experiente não é tarefa fácil para os varejistas. Sheth, Mittal e Newman (2001) mostram que os vendedores de uma loja de preços baixos tendem a ter menos conhecimentos sobre seus produtos que os vendedores de uma loja de especialidades, como no caso de automóveis e pacotes de viagem. Supermercados não se enquadram em itens de preços altamente rentáveis, mas não significa que o consumidor deixará de pedir informações. Vendedores profissionais e experientes ajudam não só oferecendo seus conhecimentos, mas também auxiliando o cliente a escolher um produto que atenda às suas necessidades. O atendimento não acaba quando o consumidor passa pelo caixa com suas compras. O pós-compra refere-se à assistência que o varejo suporta para seu consumidor. Este valor de atendimento é gerado enquanto o produto ainda é utilizado ou consumido (SHETH; MITTAL; NEWMAN, 2001). Na busca da satisfação e fidelização do consumidor, empresas criam o Serviço de Atendimento ao Consumidor ou o Centro de Respostas ao Consumidor, para que se torne mais cômoda a experiência de compra, além de contribuir para a relação com clientes. Quando se tem uma equipe disposta ao atendimento do consumidor, existe a certeza de sucesso, pois esta conhece as necessidades de seu público. De acordo com os autores Sheth, Mittal e Newman (2001), o valor do atendimento força o varejo a afastar-se de uma mentalidade voltada apenas para a produção e venda, e o orienta para um marketing corpo a corpo, mais próximo do consumidor.

\subsubsection{Localização e tamanho da loja}

Levy e Weitz (2000) afirmam que a decisão mais importante para o futuro de um supermercado é a sua localização. Identificar qual o melhor ponto para a instalação da loja é um fator crítico, pois não pode ser alterado facilmente ao longo do tempo. Isso não se refere ao conforto do proprietário do estabelecimento ou preferências do fornecedor, mas sim, ao comportamento do consumidor. Para Bernardino et al. (2004), o tamanho da loja representa Revista Eletrônica de Estratégia \& Negócios, Florianópolis, v.6, n.3, set./dez.2013. 
a preferência de compra do consumidor e isto envolve não só o estabelecimento, mas também a variedade de produtos e o perfil de serviço da loja.

$\mathrm{Na}$ busca pela satisfação da necessidade do consumidor o lojista precisa identificar qual é a preferência também de localização do cliente. Ao longo do tempo, os empresários escolhiam o bairro para se instalar de acordo com o produto/serviço comercializado. Em algumas cidades, a tradição é mantida, concentrando especialidades como, por exemplo, bairro de comércio para noivas, oficinas mecânicas, comércio de luxo, concessionárias, dentre outros. Segundo Daud e Rabello (2007), na queda da inflação, os hipermercados se instalaram distantes da casa dos clientes, os consumidores recebiam o pagamento do mês e se dirigiam até esses estabelecimentos para realizarem compras para todo o mês. Hoje o cenário é diferente: o cliente visita lojas próximas às suas casas com mais frequência, em alguns casos, mais do que uma vez por semana. Para compras diárias, os consumidores não se sentem encorajados a percorrerem grandes distâncias. O pequeno varejo, por estar mais próximo do cliente, é quem se destaca na busca de conveniência para o consumidor. Segundo Blackwell, Miniard e Engel (2005), as percepções dos consumidores sobre a localização da loja são mais importantes do que a localização real. Localização para o consumidor representa a distância e o tempo gasto quando vão até a loja para comprar.

Após o levantamento das categorias de análise com base na literatura, em uma ida a campo foi realizada uma pesquisa com consumidores, objetivando-se identificar outras categorias que não foram apresentadas nos estudos anteriores. A seguir, desenvolvese o referencial teórico dessas categorias.

\subsubsection{Ambiente físico}

Hawkins, Mothersbaugh e Best (2007) apresentam o conceito de ambiente físico e sua importância na tomada de decisão do consumidor, como, por exemplo, o layout. Todos os fatores e sentimentos de uma loja trabalham em harmonia na busca de influenciar o ato de compra do consumidor, com o objetivo de adequar a loja ao seu público-alvo. Além da soma de todas as características físicas do ambiente do supermercado, o consumidor julga a imagem da loja. Como atributo de qualidade, o lojista pode identificar o 
comportamento do consumidor no estabelecimento, quanto tempo permanece no supermercado, a qual setor vai com mais frequência e até a preferência de compra.

Para os autores, os componentes de um ambiente físico estão presentes (i) nas cores, (ii) no aroma e (iii) na música. (i) A importância dada às cores é fundamental, no aspecto de entusiasmo e excitação dado ao consumidor. Certas cores e características estimulam o ser humano e a atenção, como as cores vivas. Na busca de encorajar a compra por impulso, os varejistas podem utilizar cor vermelho que tem a capacidade de atrair atenção e gerar sentimentos de excitação. De acordo com Daud e Rabello (2007), lojas que valorizam a alta rotatividade de consumidores, como as lojas de departamento, utilizam as cores quentes como vermelho, laranja e amarelo na busca de criar desconforto. Já o contrário, as cores frias, criam uma atmosfera de bem-estar, para que assim o cliente permaneça a maior parte do seu tempo no ambiente de loja. (ii) A indústria de aromatização tem se desenvolvido em torno do uso de essências para ambientes. Vendo o crescimento do mercado e a oportunidade dada aos profissionais de marketing, os varejistas vêm fazendo uso recorrente desta ação em suas lojas. Na obra de Guéguen (2010), o pesquisador Jacob realiza um estudo na entrada de um supermercado de bairro. Pesquisadores espalhavam um aroma alimentar facilmente identificado pelos consumidores (aroma de frango assado ou aroma de chocolate derretido), além de fazerem o experimento sem aroma. O consumidor era discretamente vigiado e seguido para descobrir a direção inicial de sua compra. Concluiu-se que o aroma é um alto indicativo de orientação de escolha dentro do supermercado, já que consumidores expostos ao estimulo tendiam a consumir mais produtos correlatos. $\mathrm{O}$ aroma tem grande importância para a permanência do consumidor naquele local de compra. Um ambiente aromatizado produz maior intenção de visitar a loja novamente além de reduzir o sentimento de tempo gasto com compras pelo consumidor (HAWKINS; MOTHERSBAUGH; BEST, 2007). (iii) No estudo das emoções, a música ambiente é um elemento relevante, pois o comportamento do consumidor pode ser altamente impactado pelo contexto musical, impulsionando compras ou repelindo consumidores. Hawkins, Mothersbaugh e Best (2007) mostram que havendo público-alvo, o varejo deve conhecer suas preferências. Na busca de combinar ritmos com o estilo aceito pelos seus clientes, o comerciante pode obter resultados positivos, como a satisfação e o prazer. 0 consumidor pode passar mais tempo na loja, consumir mais, além de perceber a qualidade Revista Eletrônica de Estratégia \& Negócios, Florianópolis, v.6, n.3, set./dez.2013. 
do serviço prestado pelo supermercado. Uma música rápida tocada no supermercado incita o consumidor a fazer suas compras mais rapidamente (GUÉGUEN, 2010).

\subsubsection{ESTACIONAMENTO}

O estacionamento é definido como uma pré-transação do supermercado, caracterizada pelas informações que o consumidor leva em conta antes de chegar ao estabelecimento. Em um supermercado, um estacionamento amplo e com vagas disponíveis traz segurança, conforto, além de reter o cliente na loja (MATTAR, 2011). Na busca por atender às necessidades dos consumidores motorizados, os proprietários de supermercado a cada dia têm adaptado novos serviços ao estacionamento do supermercado, por exemplo, lava rápido, caixas eletrônicos e calibragem dos pneus.

Daude Rabello (2007) apontam o exemplo da rede americana de supermercados Stew Leonard's. Para os clientes motorizados, em vésperas de feriado e dias de maior movimento, adotam uma estratégia de gratificação para os clientes que param o carro nas vagas mais distantes do estacionamento, ou até mesmo fora do supermercado, dando-lhes um sorvete. Para reter o cliente na loja, o estacionamento da Stew Leonard's não é destinado apenas aos carros. Os pais deixam seus filhos em uma área que conta com uma pequena fazenda com animais. Os estacionamentos são dotados de identificação e sinalização com espaço para propagandas e mídias, este espaço pode ser vendido para fornecedores ou utilizado para o próprio supermercado.

\subsubsection{Qualidade}

De acordo com McGoldrick (2005), o supermercado é um serviço que deve proporcionar ambiente agradável e ofertar uma combinação de produtos, em uma localização conveniente e com horário de atendimento mais longo. O objetivo dos supermercadistas passa a ser regular à qualidade do serviço oferecido, ou seja, fazer as coisas bem e com confiabilidade. Os serviços prestados pelos supermercados têm uma vida útil curta, pois há facilidade de serem copiados pelos concorrentes. Determinados centros comerciais em parceria com os lojistas criaram níveis de serviço visando à garantia da Revista Eletrônica de Estratégia \& Negócios, Florianópolis, v.6, n.3, set./dez.2013. 
qualidade para os consumidores em geral, para motoristas, famílias e deficientes físicos. Para a obtenção dessas informações, são usados os "clientes misteriosos" que visitam as lojas e fazem uma avaliação objetiva do serviço prestado (McGOLDRICK, 2005).

A qualidade é também uma oferta para o cliente e ela caminha junto com o preço do produto. Kotler e Keller (2006) identifica o preço sob a perspectiva da qualidade, desta vez mostra que muitos consumidores usam o preço como indicador de qualidade. Muito visto em supermercado, quando não se tem informações sobre a verdadeira qualidade do produto, o preço torna-se o principal indicador daquele produto. 0 preço indica o grau de qualidade percebido do produto: um item com preço baixo indica baixa qualidade (percebida), assim como alto preço indica um produto aparentemente mais confiável (ZEITHAML, 1988). Quanto mais os consumidores confiarem no preço do produto como critério para medir a qualidade, menos sensíveis ao preço provavelmente serão e, se avaliarem o produto como de alta qualidade o comprador pode até esperar que o preço seja maior (DIAMANTIPOULOS, 2005).

\subsubsection{Composto Promocional}

Os varejistas dispõem de muitos meios para se comunicarem com seus clientes regulares, tanto no comércio quanto por guerrilhas ou através de mala direta enviada para os que têm contas ou cartões de fidelidade. A promoção é conhecida como o 4으 P do mix de marketing e, de acordo com Queiroz, Souza e Gouvinhas (2008), tem como objetivo desenvolver programas para induzir o consumidor a comprar por meio de informações, motivações, entre outros. Uma pesquisa realizada com 420 consumidores pelo Programa de Administração de Varejo (Provar) em São Paulo verificou a relação de compra entre mulheres e homens, e viu que elas compram mais por impulso do que eles, ou seja, têm maior dependência com as promoções em supermercados e em hipermercados. Observa-se que a diferença é pequena, mostrando que os dois gêneros estão sujeitos aos estímulos de consumo (BELLO, 2002 apud QUEIROZ; SOUZA; GOUVINHAS, 2008).

O objetivo da propaganda em relação a uma marca é melhorar as atitudes. Por sua vez, o propósito da promoção é converter atitudes favoráveis em vendas. A promoção 
pode fechar uma venda, pois ocorre no próprio comércio, enquanto a propaganda ocorre distante, realizada muitas vezes pelo próprio fornecedor (PEATTIE; PEATTIE, 2005).

De acordo com Peattie e Peattie (2005), além da propaganda que é mais utilizada, alguns varejistas também fazem uso do patrocínio como veículo promocional, o que evita a saturação de propagandas convencionais na mídia, como faz o Grupo Pão de Açúcar, patrocinador oficial das atletas da Seleção Brasileira de Futebol e do atletismo. A cada dia o varejo fica mais sofisticado em suas atividades conhecidas como relações públicas, que não são dirigidas apenas aos consumidores, mas também aos acionistas, governos, fornecedores, empregados e sindicatos. O quadro 2 sintetiza as principais formas de promoção, propostas por Peattie e Peattie (2005).

Quadro 2 - Principais formas de promoções de consumidor

\begin{tabular}{|l|l|l|}
\hline Promoção & Principais Setores Usuários & Exemplos \\
\hline $\begin{array}{l}\text { Desconto de } \\
\text { preço e } \\
\text { liquidações }\end{array}$ & $\begin{array}{l}\text { Empresas de bens de } \\
\text { consumo rápido, varejistas. }\end{array}$ & $\begin{array}{l}\text { Liquidações de Janeiro. Campanhas de varejistas como: } \\
\text { Black Friday. A Amazon oferece um desconto de 40\% no } \\
\text { "Primeiro Aniversário" de um cliente. }\end{array}$ \\
\hline $\begin{array}{l}\text { Condições de } \\
\text { pagamento }\end{array}$ & $\begin{array}{l}\text { Produtos de consumo } \\
\text { duráveis, varejistas. }\end{array}$ & $\begin{array}{l}\text { Ofertas de crédito sem juros. Em 2001, marcas como } \\
\text { Compaq e Microsoft usaram promoções: “Compre agora, } \\
\text { pague depois". }\end{array}$ \\
\hline $\begin{array}{l}\text { Pacotes múltiplos } \\
\text { e compras } \\
\text { múltiplas }\end{array}$ & Bens embalados, varejistas. & $\begin{array}{l}\text { A Kodak usou uma oferta "3 por 2" para impulsionar sua } \\
\text { participação no momento crucial da estação de } \\
\text { inverno/festas de fim de ano. Estratégia também usada } \\
\text { em padarias. }\end{array}$ \\
\hline Concursos & Bens embalados, varejistas. & $\begin{array}{l}\text { "Caça ao Tesouro" de 40 milhões da McDonald's. } \\
\text { Campanha “Ganhe um Carro por Dia durante Cem Dias" } \\
\text { da Heinz. }\end{array}$ \\
\hline $\begin{array}{l}\text { Cartões de } \\
\text { fidelidade }\end{array}$ & Varejistas. & $\begin{array}{l}\text { A loja Boots, especializada no varejo de beleza tem mais } \\
\text { de 13 milhões de membros e mais de 50\% de suas vendas } \\
\text { são feitas com o cartão. }\end{array}$ \\
\hline
\end{tabular}

Fonte: Peattie e Peattie (2005, p. 328).

\section{METODOLOGIA DE PESQUISA}

\subsection{COLETA DE DADOS}

Considerando a abordagem qualitativa desta pesquisa e sua natureza exploratória, entendeu-se que a melhor escolha metodológica para coleta de dados foi o uso de Grupos Focais. Segundo Flick (2009), as entrevistas em grupo são uma forma de amplificar a situação de entrevista. De acordo com Patton (2002, p. 385), a definição de Revista Eletrônica de Estratégia \& Negócios, Florianópolis, v.6, n.3, set./dez.2013. 
grupo focal é "[...] uma entrevista com um pequeno grupo de pessoas sobre um tópico especifico. Em regra, os grupos são formados por 6 a 8 pessoas que participam da entrevista por um período de 30 minutos a 2 horas".

Para Oliveira e Freitas (2006), o objetivo do grupo focal é conseguir o entendimento dos entrevistados sobre o tópico da pesquisa. Para eles, não importa se essa metodologia é utilizada sozinha ou em conjunto com outros caminhos de pesquisa. A partir da perspectiva dos participantes de um grupo focal, é possível explorar novas áreas de pesquisa e aprofundar-se em questões bem conhecidas a partir da perspectiva e vivência dos entrevistados.

Em suma, o grupo focal tem um destaque por ser de baixo custo e pela riqueza de dados que é possível obter, além de ser estimulante para os entrevistados relembrarem situações que tenham vivido. Essa metodologia proporciona respostas que vão além dos limites de um único pesquisado (FLICK, 2009).

De acordo com Debus (1977), é necessário que haja um ponto em comum entre os participantes. A formação do grupo focal foi composta por associados da Associação de Aposentados e Pensionistas de Volta Redonda (AAPVR), interior do estado do Rio de Janeiro. A escolha desse grupo de entrevistados foi motivada pela tendência a um grande acúmulo de experiência de compras em supermercado, além do rápido crescimento de aposentados no Brasil, seja por tempo de serviço, invalidez ou idade. Dados do IBGE apontam que a terceira idade, composta por adultos acima dos sessenta anos, em 2008 era de 15 milhões de idosos que movimentavam mais de sete bilhões de reais ao mês. De acordo com Morita (2009), o supermercado é o segundo lugar onde os idosos gastam mais, perdendo apenas para as farmácias.

Com o objetivo de delinear a quantidade de sujeitos selecionados, adotou-se como critério de qualidade, a saturação de dados, de acordo com o estudo de Fontanella, Ricas e Turato (2008). Esse encerramento de novos entrevistados funciona da seguinte forma: suspende-se a inclusão de novos participantes, assim que os dados coletados atendam à satisfação do entrevistador, apresentem informações repetidas, com redundância e que não vão acrescentar muito ao material coletado. A definição do número de participantes em cada grupo partiu de Patton (2002), que sugere compor o grupo focal com 6 a 8 pessoas. Foram realizadas quatro sessões de grupo focal, um grupo composto por Revista Eletrônica de Estratégia \& Negócios, Florianópolis, v.6, n.3, set./dez.2013. 
sete e os outros três grupos com oito entrevistados cada. O tempo de duração foi entre quarenta minutos e uma hora, dependendo sempre do tamanho do grupo e a participação dos entrevistados.

Os participantes foram avisados com antecedência pela direção da Associação de Aposentados e Pensionistas de Volta Redonda (RJ) e convidados para participar, mediante uma única condição: a de que todos frequentassem supermercado mais de duas vezes ao mês. Esta condição foi necessária para classificar os participantes pela frequência de compras e tornar a discussão em grupo mais produtiva. Os entrevistados se agrupavam nos horários estipulados para o encontro, em um local adequado para a pesquisa. O ambiente físico era composto por boa iluminação, ventilação, assentos, lanche, blocos de anotações, crachás, gravadores e filmadora. Foram tomados cuidados com o ambiente onde ocorreu a pesquisa, para que não houvesse inferência externa (DEBUS, 1977). A equipe foi composta por um moderador e uma auxiliar, que filmavam as entrevistas, além de darem suporte ao grupo, que era formado em círculos, possibilitando aos participantes se comunicarem com mais facilidade e compreenderem tudo o que era dito.

O moderador seguiu um planejamento de debates cuidadosamente apoiado em um roteiro, construído a partir do referencial teórico deste estudo. O desafio era direcionar a discussão, para que não houvesse dispersão sobre o que era abordado em cada tópico. Antes de iniciar o trabalho, cada participante preencheu um protocolo de ética, deixando-o à vontade com o processo, desobrigando-o de participar ou de responder aquilo que não lhe fosse conveniente. Toda a condução dos grupos focais foi gravada e integralmente transcrita.

\subsection{ANÁLISE DE DADOS}

A metodologia empregada neste estudo para tratamento dos dados foi a Análise de Conteúdo, que tem como objetivo produzir inferência, trabalhando com vestígios e índices relevantes. Bardin (1977) define análise de conteúdo como:

Um conjunto de técnicas de análise das comunicações visando obter, por procedimentos, sistemáticos e objetivos de descrição do conteúdo das mensagens, indicadores (quantitativos ou não) que permitam a inferência de conhecimentos 
relativos às condições de produção/recepção (variáveis inferidas) destas mensagens. (BARDIN, 1977, p. 42).

Os procedimentos referentes à Análise de Conteúdo estão sintetizados no quadro 3, em acordo com Bardin (1977).

Quadro 3 - Organização de uma Análise de Conteúdo

\begin{tabular}{|c|c|c|c|}
\hline Fase & \multicolumn{3}{|c|}{ Descrição } \\
\hline $\begin{array}{l}\text { 1a: Campus de } \\
\text { análise }\end{array}$ & \multicolumn{3}{|c|}{$\begin{array}{l}\text { Entrevistas transcritas cobriram o conteúdo utilizado para essa análise; o material foi } \\
\text { construído durante os grupos focais desta pesquisa. }\end{array}$} \\
\hline $\begin{array}{l}\text { 2ä: Definição e } \\
\text { análise das unidades } \\
\text { de texto }\end{array}$ & \multicolumn{3}{|c|}{$\begin{array}{l}\text { A seleção foi feita de ordem aleatória, mas foi utilizado todo o material, não tendo uma } \\
\text { amostragem de entrevistas transcritas. }\end{array}$} \\
\hline $\begin{array}{l}\text { 3a: Tipos de } \\
\text { unidades de registro }\end{array}$ & \multicolumn{3}{|c|}{$\begin{array}{l}\text { Entre as quatro entrevistas, destaca-se a análise das Unidades Semânticas, onde } \\
\text { implica juízo humano. }\end{array}$} \\
\hline \multirow{2}{*}{$\begin{array}{l}\text { 4a: : Etapas de análise } \\
\text { de conteúdo }\end{array}$} & 1․ Etapa & 2a Etapa & 3a Etapa \\
\hline & $\begin{array}{l}\text { Na pró-análise foi feita a } \\
\text { leitura de todo o material. } \\
\text { Surgiram então as } \\
\text { afirmações e negações em } \\
\text { função do referencial } \\
\text { teórico já construído. Não } \\
\text { se descartou nem omitiu } \\
\text { nada. Aproveitou-se a } \\
\text { totalidade dos textos. } \\
\text { Foram levantados os } \\
\text { índices, que são os temas } \\
\text { que se repetem com muita } \\
\text { frequência. Com o } \\
\text { material preparado, } \\
\text { destacaram-se as } \\
\text { semelhanças e contrastes, } \\
\text { partindo para próxima } \\
\text { etapa. }\end{array}$ & $\begin{array}{l}\text { Os dados brutos são } \\
\text { transformados e } \\
\text { agregados em unidades, } \\
\text { para que possam } \\
\text { descrever as } \\
\text { características } \\
\text { relacionadas ao conteúdo. } \\
\text { O recorte de frases foi a } \\
\text { unidade de registro } \\
\text { utilizada. Presença, } \\
\text { frequência e intensidade, } \\
\text { foram as três regras de } \\
\text { interesse para esse estudo } \\
\text { apontar a significância, a } \\
\text { importância que é dada e a } \\
\text { amplitude das opiniões } \\
\text { para considerar o que é } \\
\text { mais significativo. As } \\
\text { categorias foram baseadas } \\
\text { no Referencial Teórico, de } \\
\text { forma pertinente, objetiva } \\
\text { e produtiva. }\end{array}$ & $\begin{array}{l}\text { A inferência e } \\
\text { interpretação dos } \\
\text { resultados foram feitas } \\
\text { sempre de acordo com o } \\
\text { Referencial Teórico, } \\
\text { buscando essa relação com } \\
\text { os dados em comum. } \\
\text { Quanto à inferência, de } \\
\text { forma minuciosa, teve } \\
\text { como objetivo encontrar a } \\
\text { aparente realidade } \\
\text { escondida nas palavras, } \\
\text { àquelas afirmações } \\
\text { escondidas atrás de uma } \\
\text { fala anunciada. }\end{array}$ \\
\hline
\end{tabular}

Fonte: Desenvolvido pelos autores com base em Bardin (1977).

\section{RESULTADOS}

Os grupos focais sugeriram poucas modificações na abordagem dada pelos autores, acredita-se que, motivados pela alteração de suas respectivas preferências comportamentais, específicas do segmento terceira idade. Casos em que aconteceram tais divergências serão abordados conjuntamente com o que será apresentado pelos Revista Eletrônica de Estratégia \& Negócios, Florianópolis, v.6, n.3, set./dez.2013. 
participantes do grupo focal e nas considerações finais. Os trechos relevantes são apresentados a seguir, transcritos da forma dita pelos entrevistados, preservando e ressaltando as intervenções. O nome de cada participante foi descrito com as iniciais. Cabe ressaltar que a organização do texto reforça a existência das categorias descritas pela literatura (preço, serviços prestados, atendimento e localização), além das categorias que emergiram no estudo (ambiente físico, qualidade e composto promocional).

Quanto à localização e ao tamanho do supermercado, embora alguns manifestem maior atração pelos grandes nomes, é possível identificar boa parte dos elementos valorizando aspectos encontrados apenas em pequenos mercados de vizinhança como, por exemplo, proximidade do cliente, comodidade e praticidade no atendimento. As assertivas reforçam os achados:

Eu vou mais de uma vez no mês ao supermercado. Como ele é perto da minha casa eu prefiro e ele é do grande, lá tem mais opção, às vezes é maior as promoções também. O mercado pequeno já não oferece muita promoção, mais variedade eu encontro no supermercado grande. (L)

Faço compra uma vez por mês de tudo depois todo fim de semana vou ao mercado comprar aquilo que está faltando. Fico mais à vontade no mercado perto da minha casa, no mercado grande eu fico perdida [...]. (V).

Eu gasto mais no (nome de mercado) que eu vou no dia da feira de sábado que é do lado, trabalho pra comprar as coisas que ele gosta. É o meu filho que come muito (E).

No mercado grande é tudo cheio, no (nome de supermercado de grande porte) tinha uma fila tão grande que eu desisti. [...] No grande eles nem dão atenção pra gente, mas depende dos meninos, tem quem pergunta meu nome e despede de mim. Mas no pequeno é bem mais fácil já que eles me conhecem. (AM). (Entrevista realizada pelos autores, 2013).

Blackwell, Miniard e Engel (2005) confirmam que é da preferência do consumidor que o tempo gasto e a distância percorrida sejam a menor possível. Na fala apresentada pelos clientes entrevistados, verifica-se a preferência de compras próximas à feira de rua. A situação corrobora os apontamentos de Daud e Rabello (2007), em que a densidade populacional ao redor da loja influi nas compras. O cliente percebeu que o deslocamento pelo preço nem sempre vale a pena, podendo ser melhor ficar perto de casa ou aproveitar o caminho do trabalho. 
Em relação ao ambiente físico, reflete-se a preocupação do consumidor quanto à limpeza do supermercado. Aparentemente, a relação de iluminação, limpeza e os odores do ambiente são fatores decisivos. Além disso, o conforto térmico aparece como um aspecto crítico nas compras, podendo comprometer inclusive, o ticket médio.

O cheiro, a gente tem que levar em conta sim. Eu compro sempre e dou uma olhadinha se tiver sujo e até com mau cheiro eu acabo não comprando nada. Está muito quente os supermercados, a gente nem consegue ficar muito tempo lá, ai procura um lugar mais arejado pra comprar onde eu estou bem. (AI).

O cheiro de pão quente é uma delícia. Isso acontece comigo por causa do cheiro eu vou lá e compro mais. [...] A iluminação e as cores está ótima, sempre tem alguém limpando o chão, a limpeza pra mim é ideal, eu gosto muito do supermercado por causa disso, sempre que vou tem alguém limpando. (G). (Entrevista realizada pelos autores, 2013).

Em função da precariedade da limpeza, muitos consumidores estão abrindo mão de comprar no setor de hortifrutigranjeiros e de açougue dos supermercados, optando alternativamente por quitandas e açougues convencionais. Em relação ao setor de hortifrutigranjeiros, participantes do grupo focal relatam que há muita ocorrência de FLV (frutas, legumes e verduras) estragadas nas gôndolas, apesar da aparência disfarçada, em alguns casos até aceitáveis, mas inapropriadas para o consumo. A reposição de frutas e armazenamento nas quitandas é um diferencial para os consumidores, que dizem ser mais selecionadas que aquelas encontradas no supermercado. De acordo com Guéguen (2010), por causa de um aroma desagradável em um setor, toda a loja pode ser prejudicada, uma vez que a permanência do consumidor é, em geral, menor. A declaração de um dos clientes reforça os achados da literatura:

Tem supermercado que eu vou e tenho nojo, no supermercado lá que não vou falar o nome, tem sempre alguma coisa escorrendo, eu não compro no açougue de mercado então eu não confio, prefiro o açougue mesmo que tem a carne já resfriada. Onde eu vou sempre está iluminado e limpo, é um atrativo. (AM). (Entrevista realizada pelos autores, 2013).

O açougue convencional tornou-se a opção de muitos consumidores, em virtude de questões como: mau odor, limpeza precária do setor, carnes congeladas mais de uma vez, ou ainda, descongeladas e vendidas como se fossem resfriadas. A procedência da carne 
é um fator avaliativo para o consumidor, que opta pela compra em açougues, ainda que paguem mais pelos produtos.

Apontado como fundamental, o estacionamento é uma necessidade de todos os entrevistados, mesmo em supermercados de vizinhança, que são usados quando clientes fazem grandes compras. Tratando-se de centro comercial, com muita frequência os consumidores deixam o automóvel no estacionamento do supermercado e fazem outras atividades nas proximidades, tendo a opção de pagar uma taxa ou realizar compras no supermercado. Essa medida é correta e os entrevistados estão conscientes que o estacionamento do supermercado é para o tráfego de pessoas no estabelecimento e não em outras lojas. Como o público pesquisado, em geral apresenta limitações, ou ainda dificuldades de locomoção, sobretudo com carga, a disponibilidade de estacionamento aparenta ser um elemento decisivo para a escolha do estabelecimento:

Ter que pagar rotativo pra ir no supermercado comprar as coisas não dá, eu compro aonde tem estacionamento. Porque às vezes tenho que parar o carro longe e ir andando, e com a nossa idade não tem como fazer isso mais. Eu saio de casa pra resolver um monte de coisa, só depois que vou no supermercado, é caminho, eu paro no estacionamento deles e tenho que comprar rápido porque lá tem taxa se passar do tempo. (LA). (Entrevista realizada pelos autores, 2013).

A questão da permanência em supermercados quando são cobradas taxas de estacionamento, direcionam a preferência dos consumidores aos pequenos estabelecimentos, em contraposição aos hipermercados. Os consumidores expõem a preocupação de não encontrarem o que procuram a tempo e, ao final, a compra não ser tão vantajosa quanto aparentava inicialmente. De acordo com Mattar (2011), os supermercados estão aperfeiçoando e instalando novos serviços para manterem a clientela por mais tempo no estabelecimento, como, por exemplo, caixas eletrônicos e lava-jato. Para os consumidores não motorizados, deve-se levar em conta a proximidade do supermercado com pontos de ônibus e táxi. Isso reafirma a necessidade de escolha de ponto comercial que atenda com conforto e acessibilidade a todos os consumidores, de todas as faixas etárias e possibilidades de locomoção.

Durante o grupo focal, situações desagradáveis sobre o mau atendimento aos consumidores (neste caso, pertencentes à chamada terceira idade) foram mais ressaltadas pelos entrevistados. É necessário que os supermercados avaliem o atendimento prestado Revista Eletrônica de Estratégia \& Negócios, Florianópolis, v.6, n.3, set./dez.2013. 
pelos seus colaboradores. Os clientes estão sempre prontos a recordarem episódios negativos que vivenciaram, os quais, em sua grande maioria, não são expostos ao responsável do setor de concorrência do fato. Esses clientes saem do estabelecimento sem efetuarem a compra e não retornam, ou preferem não serem atendidos pelo(s) funcionário(s) que os atendeu mal.

Outro dia, eu não vou falar o nome, mas fui comprar um frango assado, perguntei o valor pro menino ele disse: 17 reais, ai eu disse: isso tudo? Ele respondeu: Está vendo o preço não? Então pra que pergunta? Essas coisas assim me deixam muito triste sabe, foi perto dos outros clientes também. Eu deixei de comprar, primeiro pelo preço e segundo pela falta de educação, eu continuo comprando até hoje, é como se nunca tivesse existido [...] As pessoas deixam de comprar, eu conheço gente que não compra mais porque fui mal atendido, eu continuo comprando porque lá me interessa, eu gosto do supermercado, mas nunca mais quero que ele me atenda. (E). (Entrevista realizada pelos autores, 2013).

Sheth, Mittal e Newman (2001) reforçam a relevância de dois momentos de atendimento, o pré e o pós-compra. Para o consumidor, a pré-compra começa em casa, quando identifica a necessidade de algo e, logo após, escolhe onde realizar as compras. Em um açougue, por exemplo, o açougueiro deve estar munido de informações suficientes do corte e do preço, tratar os clientes com cordialidade e atender às suas necessidades de compra (ALLARCON, 2010). Aquele açougueiro que oferece novos produtos e comunica uma promoção ou oferta especial agrada o consumidor. Quando o cliente consome o produto adquirido e é satisfeito, reforça psicologicamente o acerto de sua decisão de compra, posteriormente retornando àquele supermercado, caracterizando o pós-compra. Quando o atendimento é diferenciado, o consumidor está disposto a vivenciar novas experiências ao visitar o supermercado, além de repassar o bom atendimento aos seus conhecidos, através da recomendação do local.

O comportamento do consumidor tem se modificado em relação ao preço e às formas de pagamento disponibilizadas. Tomando-se por base os achados da análise dos dados colhidos na pesquisa, aparentemente poucos clientes gastam seu tempo percorrendo diversos supermercados em busca de melhores preços, dados a disponibilidade de encartes promocionais e a diversidade de informações dispostas na mídia. Os consumidores entrevistados contam com um limite aceitável de preços por produtos como, por exemplo, itens básicos apontados na pesquisa como óleo, arroz e açúcar. Durante dias úteis, quando Revista Eletrônica de Estratégia \& Negócios, Florianópolis, v.6, n.3, set./dez.2013. 
clientes procuram por poucos itens de consumo, não se dispõem a se locomoverem por pequenas diferenças em preço, conforme apontado nas entrevistas. As estratégias adotadas pelos supermercados de baixarem o preço de alguns itens durante todo o mês e não só durante a quinzena, como ofertas diferentes a cada dia, impulsionam o consumidor a visitar mais a loja e adquirir mais, conforme corrobora a entrevistada:

Compra bruta pra mim é o arroz, açúcar, feijão, óleo, carne também nem se fale, gasto muito. Meu marido às vezes vai no mercado comprar pouca coisa de frutas, ele acaba vendo o preço do arroz e açúcar cristal, mas ai ele fica olhando lá e vê outras coisas que tá na oferta, vê e traz. Ai eu falo: Amor pra que você trouxe tanto arroz? Tá na promoção né, tem que comprar. Deixa essa reserva ai. (V). (Entrevista realizada pelos autores, 2013).

Uma estratégia adotada pelas grandes corporações é manter produtos de marca própria, dificultando a concorrência por preços. Os produtos de marca própria costumam ser mais baratos que os produtos de marcas diversas e, dessa forma, é mais econômico para o consumidor adquirir produtos do próprio estabelecimento (MILLER, 2002). Além de demonstrar qualidade e confiabilidade para o supermercado, a qualidade do produto de marca própria contribui com a avaliação de consumidor para o supermercado como um todo. No entanto, ter uma experiência negativa com um produto pode trazer uma representação negativa para toda a marca.

A marca dos estabelecimentos também é encontrada nos cartões de fidelidade do supermercado. Possuir o cartão com a bandeira do supermercado vai além de fidelização, pois traz segurança ao consumidor, controle de crédito e facilidade na transação, já que permite parcelamento (DAUD; RABELLO, 2007). Essa facilidade de crédito, que impulsiona o consumidor a comprar além do necessário, é outro elemento do composto custo/benefício. No entanto, o dinheiro parece ser uma forma de pagamento muito usada pelo público de aposentados e terceira idade. Isso também é confirmado pela ABRAS, quanto aos meios de pagamentos, o dinheiro continua a liderar com $36,8 \%$. Os cartões de crédito representam $33,7 \%$, sendo cartões de crédito de terceiros $(21,1 \%)$ e cartões de crédito próprios $(12,6 \%)$. O cartão de débito representa 16,9\% (CASTRO; FERREIRA, 2012).

As falas coletadas no grupo focal confirmam as proposições de Kotler e Keller (2006) de que preço e qualidade caminham juntos. Conforme apontado na análise de resultados referentes à categoria preço, o cliente parece memorizá-los, criando assim seu Revista Eletrônica de Estratégia \& Negócios, Florianópolis, v.6, n.3, set./dez.2013. 
limite, ou seja, até quanto está disposto a pagar por um produto. Quando percebe uma diferença muito significativa de preço, em geral desconfia da qualidade daquele produto, principalmente sobre produtos perecíveis:

\begin{abstract}
Quando vou no supermercado eles colocam um freezer cheio de produtos com preço baixo a primeira coisa que olho é a validade, vira e mexe está pra vencer em poucos dias. A gente não é boba, se não está tendo saída do produto eu não compro, vai ficar agarrado do mesmo jeito lá em casa(R).
\end{abstract}

Eu costumo comprar torta na padaria do supermercado, tem dia que custa entre 30 e 40 reais, torta média, eu compro e é o mesmo preço de uma confeiteira, mas se a torta é gostosa, sempre tem ali, não preciso ligar antes e é uma delícia (E). (Entrevista realizada pelos autores, 2013).

$\mathrm{Na}$ fala anterior, confirmam-se as características do pós-compra. O consumidor memoriza o local onde será efetuada a compra e o evoca ao identificar a necessidade daquele produto. Em situações como essa, o cliente preocupa-se pouco com o preço, desde que a qualidade percebida daquele produto seja elevada, ou ainda, que caiba nas expectativas previamente desenvolvidas.

Uma vez que a totalidade do público entrevistado usufruiu de um desconto concedido aos associados da AAPVR, acabam que não usam o desconto do cartão de fidelidade concedido por muitos supermercados da região. No entanto, são fortemente influenciados pelos descontos promocionais. Para os que pesquisam preço, a mídia mais usada é o encarte distribuído temporariamente pelos supermercados. Já para aqueles que não pesquisam preço no local, a televisão é ainda a mídia mais eficaz, sobretudo para promoções de curta duração. Nesse tipo de promoção (de curta duração), o público masculino aparenta comportar-se diferentemente do público feminino e, por conseguinte, desenvolve atitudes distintas, normalmente efetuando compras maiores que aquelas demandadas pelo público feminino:

A televisão ajuda muito [...] ele foi comprar foi sabão em pó, apareceu lá que o Omo estava na promoção, ele foi comprar acho que 5 caixas, era o limite que eles colocam por pessoa, se eu soubesse ia junto. ( $\mathrm{J}$ - feminino).

Quando vou comprar alguma coisa é diferente, sempre dou uma olhadinha nos outros preços do supermercado tendo coisa que quero e com preço bom eu levo, gosto de ir pouco ao supermercado se não eu gasto muito toda vez que vou. (E masculino).

Revista Eletrônica de Estratégia \& Negócios, Florianópolis, v.6, n.3, set./dez.2013. 
Essas promoções eles sempre levam uma vantagem porque eu sempre levo alguma coisa que não preciso, mas me agrada. (AM - masculino). (Entrevista realizada pelos autores, 2013).

Com a finalidade de estimular compras, sobretudo dos clientes mais influenciáveis por promoções, as redes criaram o dia certo de cada categoria de compra (e.g., um dia na semana para açougue; outro para hortifrutigranjeiros; outro para peixaria e padaria). Dessa maneira, o volume de vendas antes esperado para o fim de semana pode ser diluído durante todos os dias.

Ao final da realização de cada grupo focal, o moderador fazia uma análise de conteúdo de forma atenciosa e detalhada. Percebendo-se haver necessidade, agendava-se mais um grupo. Ao formar o quarto grupo, o moderador notou que já havia dados suficientes e não destacou mais diferenças relevantes entre os grupos e entre as categorias iniciais e emergentes, vez que após as transcrições, notaram-se poucas questões pontuais emergindo fora das categorias finais do trabalho. As categorias partiram do que foi construído no referencial teórico (categorias prévias ou iniciais) e outras que emergiram durante a pesquisa.

\section{CONSIDERAÇÕES FINAIS}

O objetivo de explorar razões e preferências de compras do consumidor foi alcançado através deste estudo, que empregou grupos focais para investigar questões qualitativas, construindo e reconstruindo conceitos de decisão de compra que os entrevistados apresentaram nas suas motivações de escolha do supermercado. Como conclusão desse estudo, percebeu-se que o comportamento do consumidor passou a ser mais crítico e fez com que julgasse outros fatores além do preço e localização do supermercado.

Com a facilidade de crédito, os consumidores não esperam mais seus respectivos pagamentos mensais para irem ao supermercado, frequentando-o mais vezes e os mais próximos de suas casas. Parte do público de aposentados ainda usa o dinheiro como forma de pagamento em açougues, quitandas e padarias, que não aceitam pagamentos com cartões. A localização continua sendo importante, desde que atenda às necessidades do 
consumidor. Um supermercado próximo deve conter produtos e serviços necessários para que esse público não tenha de se distanciar para as compras diárias.

Serviços como estacionamento passam a figurar como um atributo de escolha para o consumidor. Independente dos serviços de entrega em domicílio, ainda existentes em alguns estabelecimentos, o consumidor deseja a independência de levar suas compras logo após o pagamento. Nesses casos, os serviços associados passam a ser centrais, como, por exemplo, a possibilidade de um funcionário levar as compras até o carro no estacionamento. Quando o atendimento é agradável e possui serviço de boa qualidade em todos os setores, o consumidor assume se distanciar da sua área de compra para vivenciar novas experiências em outro supermercado. A mídia tem sido um elemento importante no processo de escolha, já que divulga preço. No entanto, o consumidor descobre outros atributos como o atendimento, visitando os estabelecimentos ou por meio do recebimento de recomendações (comunicação "boca a boca"). A comodidade para o consumidor não é apenas estar próximo de casa, mas estar em um ambiente físico agradável.

Dentre as principais contribuições deste estudo, cabe destacar: (i) a contribuição teórica presente no avanço do delineamento de categorias teóricas de análise, em especial, para grupos de aposentados, uma vez que a literatura contempla parcialmente tais características e, por vezes, em contextos distintos do brasileiro. Ao revelar categorias "outras", o estudo traz importante contribuição ao campo de marketing no Brasil. Dentre esses achados, destacamos a necessidade de treinamento de funcionários para atendimento a esse consumidor e o reconhecimento da necessidade de dispor produtos e serviços adequados às demandas desses clientes. (ii) Para o setor varejista, o presente estudo apresenta contribuições na sugestão de estratégias, bem como o estabelecimento de prioridades de ação, baseadas nos achados teóricos. Dentre esses elementos, pode-se destacar a avaliação do atendimento e do ambiente físico, a melhora do serviço prestado pelo supermercado, sua divulgação na mídia, critérios de localização e comodidade tais como acessibilidade, conforto térmico, emprego de elementos do marketing sensorial, além de outros elementos. Os supermercadistas devem atentar para o preço principalmente de produtos perecíveis que, uma vez baixos, não devem remeter à baixa qualidade do produto, ou ainda que este esteja inapropriado ao consumo. Identificar o perfil de comportamento do 
consumidor em cada segmento parece ser um ponto importante ao delinear o campo de trabalho no supermercado.

Uma das principais limitações desse reside em seu caráter local, já que conduzimos grupos focais em uma região delimitada, com grupos bastante específicos, ainda que tenhamos trabalhado com saturação de dados. Sugerimos o engajamento de outros pesquisadores, interessados na temática, em replicarem o estudo em outras localidades, visando a saturar as informações num âmbito nacional, especificamente com esse público que particularmente nos interessa: aposentados.

\section{REFERÊNCIAS}

ABRAS - Associação Brasileira de Supermercados. Ranking Abras 2011. Revista Super Hiper, São Paulo, v.37, n.418, p.40-46, abril, 2011.

ALLARCON, M. Além das gôndolas: como atua o promotor de vendas no supermercado. Brasília: SENAC, 2010.

ALMEIDA, A. Internacionalização de empresas brasileiras: Perspectivas e riscos. Rio de Janeiro: Elsevier, 2007.

ANDERSON, E. T.; SIMESTER, D. I. Effects of \$9 price endings on retail sales: evidence from field experiments quantitative. Marketing and Economics, v. 1, n. 1, p. 93-110, 2003.

ANDERSON, E. T.; SIMESTER, D. I. Long-Run Effects of Promotion Depth on New Versus Established Customers: Three Field Studies. Marketing Science, v. 23, n. 1, p. 4-20, Winter, 2004.

BARDIN, L. Análise de Conteúdo. Lisboa: Edições 70, 1977.

BERNARDINO, E. de C.; PACANOWSKI, M.; KHOURY, N. E.; REIS, U. A. dos. Marketing de Varejo. São Paulo: Editora FGV, 2004.

CAMAROTTO, M. R. Gestão de Atacado e Varejo. Curitiba: IESDE Brasil, 2009.

CAMPOLINA, A. S. et al. Decisões de compra dos clientes de supermercados de Anápolis. Revista de Economia da UEG, Anápolis, v. 3, n. 1, jan./jun. 2007.

CASTRO, E.; FERREIRA, C. D. Vendas iniciais do ano superam expectativas. ABRAS Economia, 2012. Disponível em: <http://www.abrasnet.com.br>. Acesso em: 23 fev. 2013.

CURTY, P. Plano Bretas. Giro News, Belo Horizonte, v. 153, p. 6-8, junho, 2009.

Revista Eletrônica de Estratégia \& Negócios, Florianópolis, v.6, n.3, set./dez.2013. 
DABDAB WAQUIL, P.; MIELE, M.; SCHULTZ, G. Mercado e Comercialização de produtos Agrícolas. Série Educação a Distância. Porto Alegre: Editora da UFRGS, 2010.

DAUD, M.; RABELLO, W. Marketing de Varejo: como incrementar resultados com a prestação de serviços. Porto Alegre: Bookman, 2007.

DEBUS, M. Manual para excelencia en la investigación mediante grupos focales. Washington: Academy for Educational Development, 1997.

DAVIES F.; GOODE, M.; MOUTINHO, L.; OGBONNA, E. Critical Factors in Consumer Supermarket Shopping Behaviour: A Neural Network Approach.

Journal of Consumer Behaviour: An International Review, v. 1, n. 1, 2001.

DIAMANTOPOULOS, A. Determinação de preços. Cap. 13. In. BAKER, M. J. Administração de marketing. 5. ed. Rio de Janeiro: Editora Campus, 2005.

BLACKWELL, R.D.; MINIARD, P. W.; ENGEL, J. F. Comportamento do Consumidor. 9. ed. São Paulo: Tomson, 2005.

FERREIRA JÚNIOR, I.; TEIXEIRA, R. M. Redes de pequenas empresas: a aplicação de uma tipologia em uma rede de supermercados. Revista de Administração Mackenzie, São Paulo, v. 8, n. 3, p. 128-152, jul./set. 2007.

FONTANELLA, B. J. B.; RICAS, J.; TURATO, E. R. Amostragem por saturação em pesquisas qualitativas em saúde: contribuições teóricas. Caderno Saúde Pública, v.24, n.1, p.17-27. 2008.

FLICK, U. Introdução à Pesquisa Qualitativa. Porto Alegre: ARTMED, 2009.

FURUTA, E. C. Razões da escolha de supermercados de vizinhança como ponto de compra. Trabalho de Conclusão de Curso. Universidade de São Paulo-USP. 2002. Disponível em: <http://www.ead.fea.usp.br/tcc/trabalhos/TCC_ErikaFuruta\%20.pdf> Acesso em: 01 ago. 2013.

GUÉGUEN, N. Psicologia do consumidor: para compreender melhor de que maneira você é influenciado. Tradução de Gian Bruno Grosso. São Paulo: Editora SENAC São Paulo, 2010.

HAWKINS, D. I.; MOTHERSBAUGH, D. L.; BEST, R. J. Comportamento do Consumidor: Construindo a estratégia de marketing. 10.ed. Rio de Janeiro: Elsevier, 2007.

HONORATO, G. Conhecendo o Marketing. Barueri: Manole, 2004.

KOTABE, M.; LEAL, R. Market Revolution in Latin America: Beyond México. New York: Elsevier Science, 2001. 
KOTLER, P. Administração de Marketing: Análise, Planejamento, Implementação e Controle. 6a ed. - São Paulo: Atlas, 2001

KOTLER, P.; KELLER, Administração de Marketing: a Bíblia do Marketing. 12.ed. São Paulo: Prentice Hall. 2006.

LEVY, M.; WEITZ B. A. Administração de Varejo. São Paulo: Editora Atlas, 2000.

MATTAR, F. N. Administração de Varejo. Rio de Janeiro: Elsevier, 2011.

McGOLDRICK, P. J. Varejo. Cap. 30. In. BAKER, M. J. Administração de marketing. 5.ed. Rio de Janeiro: Editora Campus. 2005.

MILLER, D. Teoria das compras: o que orienta as escolhas dos consumidores. São Paulo: Nobel. 2002.

MORITA, M. Público idoso pode movimentar mais de R\$ 7,5 bilhões/ano. Supermercado Moderno. São Paulo. 13 out. 2009.

OLIVEIRA, M.; FREITAS, H. Focus Group: instrumentalizando o seu planejamento. Cap.11. In: GODOI, C.K.; BANDEIRA-DE-MELLO, R.; SILVA, A. B. Pesquisa qualitativa em estudos organizacionais: paradigmas, estratégias e métodos. São Paulo: SARAIVA, 2006.

OLIVEIRA, R. N. A. Marca Própria. Rio de Janeiro: Brasport, p. 13-14, 2005.

PARENTE, Juracy. Varejo no Brasil: gestão e estratégia. São Paulo: Atlas, 2000.

PATTON, M. Q. Qualitative Evaluation and Research Methods. 3 ed. London: SAGE, 2002.

PEATTIE, S; PEATTIE, K. Promoção de Vendas. Cap. 18. In: BAKER, M. J. Administração de marketing. 5 ed. Rio de Janeiro: Editora Campus.2005.

POUNDSTONE, W. Priceless: the myth of fair value (and how to take advantage of it). New York: Farrar, Strausand Giroux Books. 2010

PIMENTA, M. L., VILAS BOAS, L. H.B., MELO, D. C., NUNES, E. F., BOAVENTURA, E. F. A Percepção de Valores na Seleção de Lojas do Varejo Alimentar: Uma Investigação Empírica nas Cidades de Uberlândia e Uberaba. In: XXXI Encontro ENANPAD. Anais... Rio de Janeiro, 2007.

QUEIROZ, T.; SOUZA, T.; GOUVINHAS, R. Estratégias de Marketing como um diferencial na escolha do supermercado de bairro. RAM - Revista de Administração Mackenzie, v. 9, n.3, p. 58-84. 2008 apud BELLO, A. A tentação da gôndola. Isto é dinheiro, 2002. Disponível em: <http://www.terra.com.br/istoedinheiro>. Acesso em: 20 jul. 2012. 
RAO, A. R.; MONROE, K. B. The effect of price, brand name, and store name on buyers' perceptions of product quality: an integrative review. Journal of Marketing Research, v.26, n.3, p.351-357, Ago. 1989.

RUBINFELD, A.; HEMINGWAY C. Feito para crescer: expandindo seu negócio na esquina ou no mundo. Porto Alegre: Bookman, 2005.

SCHINDLER, R.M. Pricing Strategies: A Marketing Approach. California: Sage Publications. 2012.

SCHINDLER, R. M.; KIRBY, P. N. Patterns of rightmost digits used in advertised process: implications for nine-ending effects. Journal of Consumer Research, p. 192-201, set. 1997. SHETH, J.; MITTAL, B.; NEWMAN, B. I. Comportamento do Cliente. São Paulo: Atlas. 2001 SIMCHI-LEVI, D.; KAMINSKY, P.; SIMCHI-LEVI, E. Cadeia de Suprimentos: projeto e gestão. Porto Alegre: Bookman, 2003.

STIVING, M.; WINER, R.A. Empirical analysis of price enfings with scanner data. Journal of Consumer Research, p. 57-86, Jun. 1997.

ZEITHAML, V. A. Consumer perceptions of price, quality, and value: a means-end model and synthesis of evidence. Journal of Marketing, v.52, n.2, p.2-22, Jul. 1988. 